\title{
Biomechanical Analysis of Top Discus Throwers Performance in Egypt
}

\author{
Raafat Abd El Monsef*, Medhat Salem*, Osama El Shaeer*, Ahmed Abd El Baky*, Mansour Abd \\ El Hameed**, Moumen Abd El Gawad*, Tareq Ghazy*
}

\begin{abstract}
:
The purpose of the presented study is to determine the specific kinematical changes related to discus throw during each phase of performance and comparing it with the specific kinematical variables in each phase in the national champion with elite athletes. a biomechanical analysis was performed on the first place thrower ( Omar el gazaly) at the national champion of Egypt 2011 $(64.74 \mathrm{~m})$, which is the 4th place during world cup champion 2006, and the first place in the African champion 2006, (PB 66.58m in 2007). All trails of the subject were recorded, but a kinematical analysis was established for the best three trails. Two video cameras ( DCR-SR68 SONY) 60 FPS were focused on the circle, one camera took the thrower from the side of his throwing Arm ( right handed) and the second one took his rear view related to the direction of throw. Both views covered a width of $5 \mathrm{~m}$ related to the center of the circle, and the analysis was performed by DARTFISH TEAM PRO 4 software program. The results show that, the delivery phase time of the subject was $0.18 \mathrm{sec}$ during his best trail, which was $20 \%$ of the total performance time, the discus resultant velocity was $25.4 \mathrm{~m} / \mathrm{s}$ and the flight time was 0.08 sec during the three trails, and that was about 9-11\% of total performance time. the average angle of release in three trails was about $\left(34.4^{\circ}\right)$. the height of release in the best trail was $1.76 \mathrm{~m}$. the total performance time of three trails was $0.880 \mathrm{sec}$ but his phases time characteristics were different.
\end{abstract}

\section{Introduction:}

$\mathrm{U}$ nderstanding human movement is one of the most difficult tasks in the field of scientific Research. The human body consists of many segments which move due to muscles contraction, so the biomechanical analysis is one of the most important tools that could help us to understand the human motion.

However in the field of sport performance, the biomechanical analysis is an important tool to evaluate athletic performance, and provide coaches and researchers with useful information which can help them to develop and achieve a high level of performance.

In athletics, the main goal of throwing events (shot put - discus throw - javelin throw hammer throw) is to achieve the Longest throwing distance, however discus throw is

\footnotetext{
* Department of Athletics, Faculty of Physical Education for Boys, Alexandria University, Egypt.

** Department of Physical Education Foundations, Faculty of Physical Education for Boys, Alexandria University, Egypt.
}

considered as one of the most difficult motor skills, which demand a high level of coordination, speed and power. In addition to it depends on the thrower's ability to move his body parts in coordinated synchronized movements. The thrower moves in a sequenced rotation movement that happens while his body is contacted to the ground (single support double support) or non-contacted (Flight phase).

The technique of the discus throwing consists of the preliminary swings, the preparation, the entry, the airborne, the transition, the delivery, and the recovery (2). Under the perspective of leg support, the discus technique is structured as the double and single support starting phases, the support less phase, and the single and double support delivery phases (12).

The official distance of discus throw is determined by speed, height and angle of release. The release characteristics are altered by each athlete's technique during the throwing procedure, so the effective technique of discus 
throw is maximizing the speed of release and optimizing the angle and height of release (11).

Many of the Previous researches have been conducted on discus throw have examined the basic biomechanical parameters of release during delivery phase (Steve Leigh et al 2010, Steve Leigh et al 2008, Ching-Hua Chiu 2008 ) such as speed, angle and height of release. Despite of these parameters determine directly the projected distance of the throw; they didn't give any indication to phases leading up to release (8).

So the lack of biomechanical researches concerning the technical details that happened during the phases of discus throw limited the coaches and athletes to understand the technical parameters of performance (3), also there is no general agreement exists among scientists or coaches about the contribution of discus throw phases, so they don't have specific informations about the phases of performance, which could help them to fix technical errors that could

happen during the performance. So a kinematic analysis of discus throw could be useful to determine the specific characteristics of each phase of performance.

The purpose of the presented study is to determine the specific kinematical changes related to discus throw during each phase of performance and comparing it with the specific kinematical variables in each phase in the national champion with elite athletes.

\section{Methods:}

\section{- Subject:}

In the presented study a biomechanical analysis was performed on the first place thrower(Omar el gazaly ) at the national champion of Egypt $2011(64.74 \mathrm{~m})$, which is the 4th place during world cup champion 2006, and the first place in the African champion 2006, (PB 66.58m in 2007)

Table 1: subject's basic information

\begin{tabular}{|c|c|c|c|c|c|}
\hline Name & Country & Height & Weight & Age & PB \\
\hline Omar El Gazaly & Egypt & 199 & 118 & 27 & $66.74 \mathrm{~m}$ \\
\hline
\end{tabular}

\section{- Data Collection:}

All trails of the subject were recorded, but a kinematical analysis was established for the phases of the best three trails. Two video cameras ( DCR-SR68 SONY ) 60 FPS were focused on the circle,, in terms of the previous studies (Vassilios 2006,Axel Knicker 1994 ) one camera took the thrower from the side of his throwing Arm ( right handed ) and the second one took his rear view related to the direction of throw. Both views covered a width of $5 \mathrm{~m}$ related to the center of the circle, the analysis was performed by DARTFISH TEAM PRO 4 software program, and compare results parameters of world's best throwers (1).

\section{Results:}

Table 2: The preparation phase

\begin{tabular}{|l|c|c|c|c|}
\hline \multicolumn{1}{|c|}{ Variables } & Unit & Trail ( 1 ) & Trail ( 2 ) & Trail ( 3 ) \\
\hline Official Distance & M & 63.28 & 64.48 & 64.76 \\
\hline Stance Distance & M & 00.82 & 00.82 & 00.75 \\
\hline CM Height & M & 01.10 & 01.11 & 01.04 \\
\hline Discus Height & M & 01.36 & 01.38 & 01.31 \\
\hline Hip Angle & $\circ$ & 139.9 & 148.0 & 146.0 \\
\hline Left Knee Angle & $\circ$ & 92.70 & 95.50 & 91.80 \\
\hline Right Arm Angle & $\circ$ & 66.00 & 69.00 & 68.00 \\
\hline
\end{tabular}

Table 2 shows some differences in the preparation parameters during all trails, the best trail had a narrow stance, low CM height and knee angle. 
Table 3: Entry phase

\begin{tabular}{|l|c|c|c|c|}
\hline \multicolumn{1}{|c|}{ Variables } & Unit & Trail ( 1 ) & Trail ( 2 ) & Trail ( 3 ) \\
\hline Official Distance & M & 63.28 & 64.48 & 64.76 \\
\hline CM Height & M & 01.19 & 01.20 & 01.11 \\
\hline Discus Height & M & 01.35 & 01.35 & 01.32 \\
\hline Left Knee Angle & $\circ$ & 102.5 & 102.6 & 102.6 \\
\hline Right Arm Angle & $\circ$ & 50.00 & 47.00 & 53.30 \\
\hline Rotation Distance & $\circ$ & 01.30 & 01.30 & 01.29 \\
\hline CM Average Velocity & $\mathrm{m} / \mathrm{s}$ & 01.14 & 01.14 & 01.17 \\
\hline
\end{tabular}

Table 3 shows many differences in the entry parameters during the best three trails of the subject, the third trail had a low CM height, low discus height, and a short rotation distance than other trails. However there were an increase in right arm angle, CM average velocity.

Table 4: Flight phase

\begin{tabular}{|l|c|c|c|c|}
\hline \multicolumn{1}{|c|}{ Variables } & Unit & Trail ( 1 ) & Trail ( 2 ) & Trail ( 3 ) \\
\hline Official Distance & M & 63.28 & 64.48 & 64.76 \\
\hline CM Height & M & 01.28 & 01.30 & 01.28 \\
\hline Discus Height & M & 01.57 & 01.59 & 01.52 \\
\hline Right Arm Angle & $\circ$ & 63.07 & 58.00 & 54.60 \\
\hline Flight Time & S & 00.08 & 00.08 & 0.080 \\
\hline
\end{tabular}

Table 4 shows a low CM height, discus height and right arm angle in the third trail than other trails during the flight phase, but there was no change in flight time.

Table 5: Transition phase

\begin{tabular}{|l|c|c|c|c|}
\hline \multicolumn{1}{|c|}{ Variables } & Unit & Trail ( 1 ) & Trail ( 2 ) & Trail ( 3 ) \\
\hline Official Distance & M & 63.28 & 64.48 & 64.76 \\
\hline CM Height & M & 01.27 & 01.33 & 01.20 \\
\hline Discus Height & M & 01.67 & 01.58 & 01.57 \\
\hline Right Arm Angle & $\circ$ & 65.00 & 58.50 & 59.70 \\
\hline Right Knee Angle & $\circ$ & 136.5 & 154.0 & 140.0 \\
\hline Rotation Distance & M & 00.77 & 00.85 & 00.83 \\
\hline CM Velocity & M/S & 03.85 & 03.86 & 04.60 \\
\hline Duration Of Rotation & S & 00.20 & 00.20 & 00.18 \\
\hline Duration Of Left Leg Rotation & S & 00.20 & 00.22 & 00.18 \\
\hline
\end{tabular}

Table 5 shows a difference in all trails in transition parameters, during the third trail there were a low CM height, discus height and a high CM velocity than the other trails. 
Table 6: Delivery phase

\begin{tabular}{|l|c|c|c|c|}
\hline \multicolumn{1}{|c|}{ Variables } & Unit & Trail ( 1 ) & Trail ( 2 ) & Trail ( 3 ) \\
\hline Official Distance & M & 63.28 & 64.48 & 64.76 \\
\hline CM Height & M & 01.10 & 01.10 & 01.09 \\
\hline Discus Height & M & 01.43 & 01.47 & 01.51 \\
\hline Right Arm Angle & $\circ$ & 62.40 & 65.00 & 70.00 \\
\hline Right Knee Angle & $\circ$ & 145.0 & 145.0 & 133.8 \\
\hline Hip Angle & $\circ$ & 168.0 & 161.0 & 156.4 \\
\hline Trunk Incline Angle & $\circ$ & 61.50 & 55.00 & 62.80 \\
\hline Distance Between Feet & M & 00.76 & 00.80 & 00.76 \\
\hline Time of Delivery Phase & S & 00.20 & 00.18 & 00.20 \\
\hline
\end{tabular}

Table 6 shows a higher discus position, a higher trunk incline angle and right arm angle during the best trail than the other trails; also there were a decrease in right knee angles during the best trail.

Table 7: Release parameters

\begin{tabular}{|l|c|c|c|c|}
\hline \multicolumn{1}{|c|}{ Variables } & Unit & Trail ( 1 ) & Trail ( 2 ) & Trail ( 3 ) \\
\hline Official Distance & $\mathrm{m}$ & 63.28 & 64.48 & 64.76 \\
\hline CM Height & $\mathrm{m}$ & 01.25 & 01.31 & 01.29 \\
\hline Angle Of Attack & $\circ$ & 34.00 & 35.30 & 21.50 \\
\hline Release Velocity & $\mathrm{m} / \mathrm{s}$ & 25.00 & 26.73 & 25.40 \\
\hline Angle of Release & $\circ$ & 31.00 & 36.00 & 36.40 \\
\hline Height of Release & $\mathrm{m}$ & 01.70 & 01.78 & 01.76 \\
\hline Discus Resultant Velocity & $\mathrm{m} / \mathrm{s}$ & 25.00 & 26.73 & 25.40 \\
\hline
\end{tabular}

Table 7 There was an increase in the angle of release during the best trail than other trails.

Table 8: General parameters

\begin{tabular}{|l|c|c|c|c|}
\hline \multicolumn{1}{|c|}{ Variables } & Unit & Trail ( 1 ) & Trail ( 2 ) & Trail ( 3 ) \\
\hline Official Distance & $\mathrm{m}$ & 63.28 & 64.48 & 64.76 \\
\hline Total Performance Time & $\mathrm{s}$ & 00.88 & 0.88 & 00.88 \\
\hline CM Average Velocity & $\mathrm{m} / \mathrm{s}$ & 01.68 & 01.70 & 01.76 \\
\hline CM horizontal displacement & $\mathrm{m}$ & 01.48 & 01.50 & 01.52 \\
\hline
\end{tabular}

Table 8 shows some additional parameters for three trails of the subject, there was no change in total performance time, but there was an increase in CM Average Velocity and CM horizontal displacement during the best trail.

Figure (1)

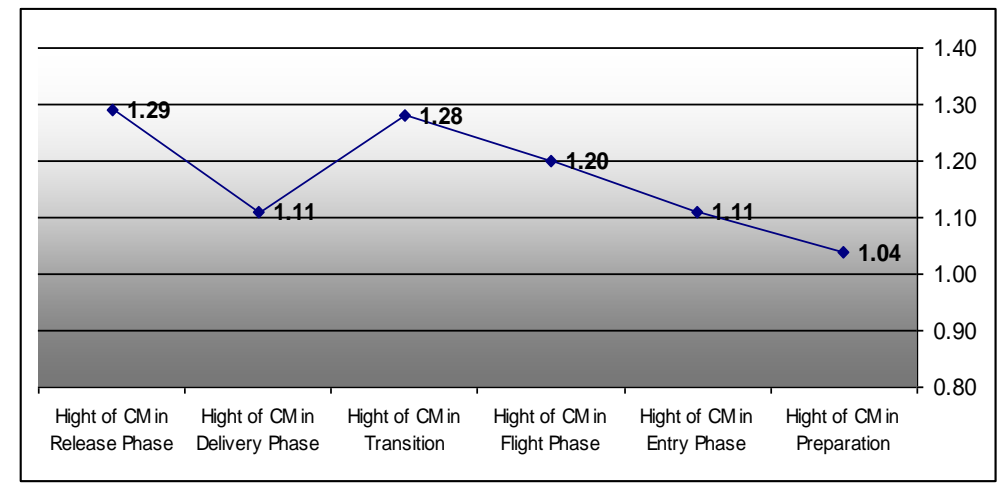

Figure (1) shows changes in CM height during best trail phases 
Figure (2)

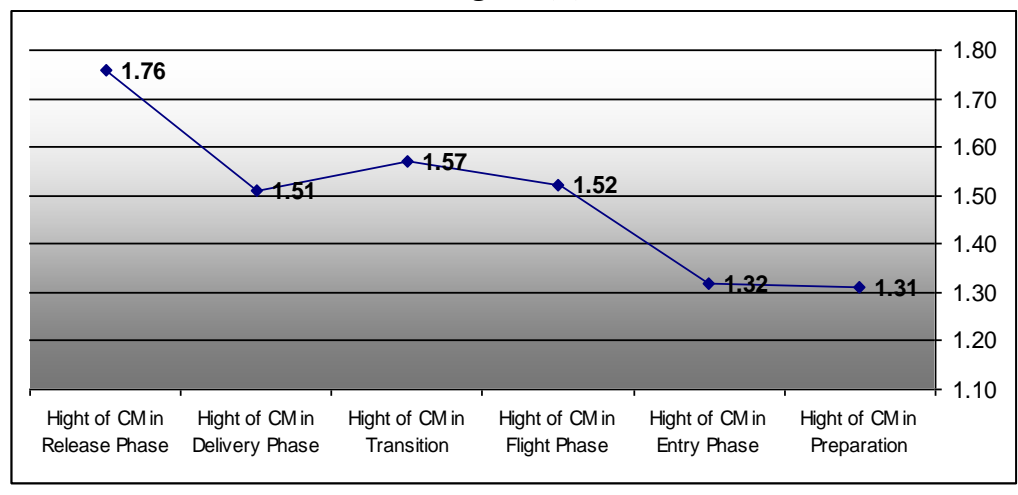

Figure (2) shows changes in discus height during best trail phases

Figure (3)

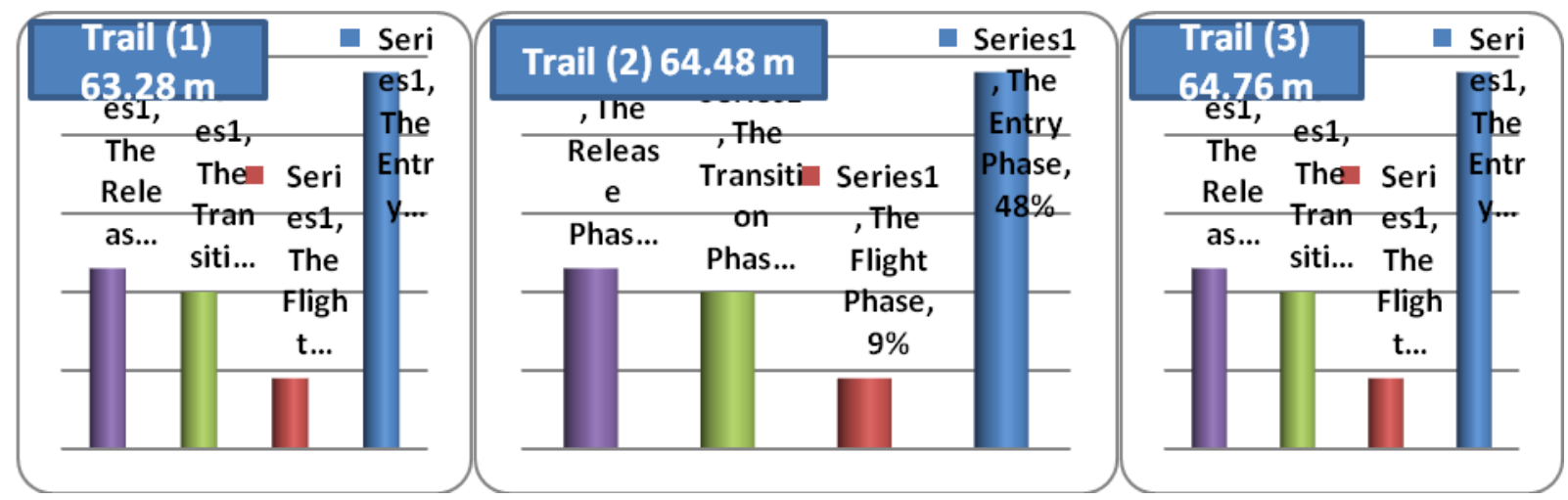

Figure (3) shows time characteristicsof three trails

Figure (4)

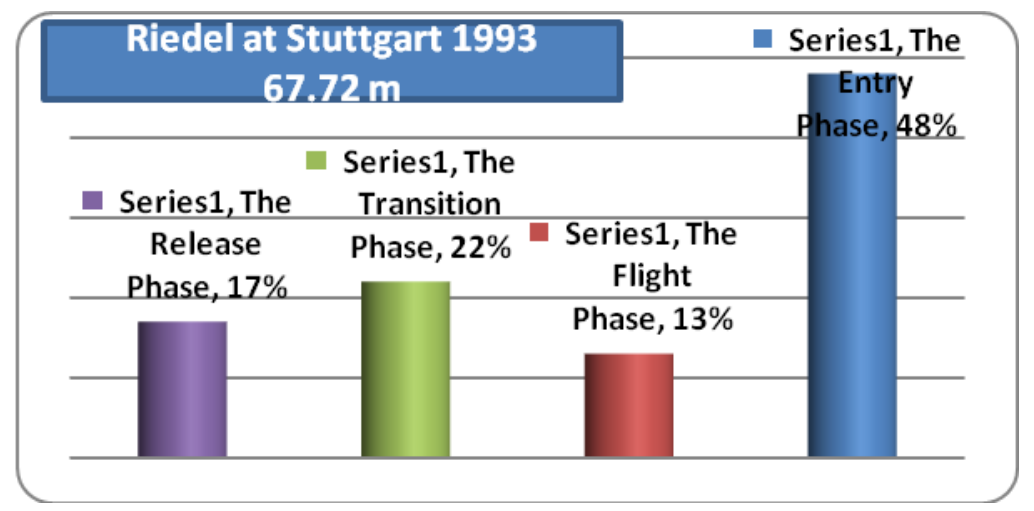

Figure (4) shows time characteristicsof Riedel at shtuttgart $67.72 \mathrm{~m}$

\section{Discussion:}

- In Table 2 During the best trail (64.74 m) the thrower had a deep body position during preparation phase, the left knee angle $\left(91.80^{\circ}\right)$, the lowest knee angle had also the lowest $\mathrm{CM}$ height $(1.04 \mathrm{~m})$ and also the lowest discus height among the three trails, the distance between feet during preparation was $75 \mathrm{~cm}$, followed by the longest entry phase (shown in table 3) which was $48 \%$ of the total performance time. And that could helped the subject to put him self in the best position during preparation and had a wide range of right leg kick which cause the longest entry time among three trails. And as a result of increasing the entry distance during this trail, the thrower could put the discus in a lower height during flight phase $(1.52 \mathrm{~m}$ ) than other trails (shown in table 4).

- In Table 6 the delivery phase time of the subject was $0.18 \mathrm{sec}$ during his best trail, which was $20 \%$ of the total performance time ( Figure 3 ), however during Stuttgart 1993 delivery phase time percents of top discus throwers were about $17 \%$ of total trial time (1), and that was 
directly correlated with discus resultant velocity during release ( Figure 4 ), At Atlanta Olympics 1996 discus resultant velocity of top discus performers was $30.80 \mathrm{~m} / \mathrm{s}$ to Riedel (GER) ( the first place $69.4 \mathrm{~m})$, and $27.18 \mathrm{~m} / \mathrm{s}$ to Dubrovschchik (BLR) ( the second place 66.6 m) (5) while in the best trail of the Subject the discus resultant velocity was $25.4 \mathrm{~m} / \mathrm{s}$ and that was suitable for his phases time characteristics , kinematical variables and the distance achieved ( $64.76 \mathrm{~m})$.

- During flight phase (shown in Table 4) flight time was $0.08 \mathrm{sec}$ during three trails, and that was about $9-11 \%$ of total performance time, while the flight time percent of top throwers during world champion in Stuttgart 1993 was about $13 \%$ of total trail time(1), and all throwers who had a flight time over $0.100 \mathrm{sec}$ during the same championship had a longer throwing distance, and that can be explained by if the thrower had a very long or a very short flight phase he wouldn't have the appropriate rotation in axial spin during delivery, However some studies have showed that flight phase time is not correlated to the distance achieved (1).

- In Table 8 the average angle of release in three trails was about $\left(34.4^{\circ}\right)$ and that similar to values shown in previous studies showed that the average angle of release of top finalists was $36.3^{\circ}$ (9), also during Stuttgart 1993 the angle of release of top finalists ranged from $34^{\circ}$ to $36^{\circ}$ (1).

- Also the height of release in the best trail was $1.76 \mathrm{~m}$ (the thrower's height 1.99), however elite throwers with the same height had a height of release about $1.49 \mathrm{~m} \mathrm{(1):} \mathrm{that} \mathrm{may} \mathrm{refers} \mathrm{to}$ the point of release of the subject was higher than usual so the subject should adjust his release height which could help him to achieve best benefits of momentum transition during delivery phase.

- Although some release parameters (height, and resultant velocity of release) of the second trail were more appropriate than the third trail, the subject achieved his best throw during the third one. That may be due to the difference of angle of attack (11) (shown in Table 7) and other variables (axial spin, pitch attitude, roll angle, relative wind velocity) which influence the discus trajectory (7).

- However the total performance time of three trails was $0.880 \mathrm{sec}$ (shown In Table 8), Specific characteristics of his trails were different, as a result, affect the release parameters and the distance achieved. Also By looking to the same subject performance in the IAAF world cup 2006 we can see that his total performance time in his best throw $(61.50 \mathrm{~m})$ was 0.900. so its clear that in this study the subject was faster than 2006 world cup also his phases time characteristics were changed.

\section{Conclusion:}

However the importance of release parameters and its effect on the throwing distance and on release velosity which have adirect relationship with the achived distance, the diffrence of the phases time charachterstics of the trial prove that the high velosity of the subject and there is ancjisity to achieve higher velosities during delivery phase, so trainers should give more attention to the specific technique excercises espcially, foot work during training to improve the release velosity which in turn improve the achieved distance. 


\section{Photo Sequence Best Trial ( $64.76 \mathrm{~m}$ )}

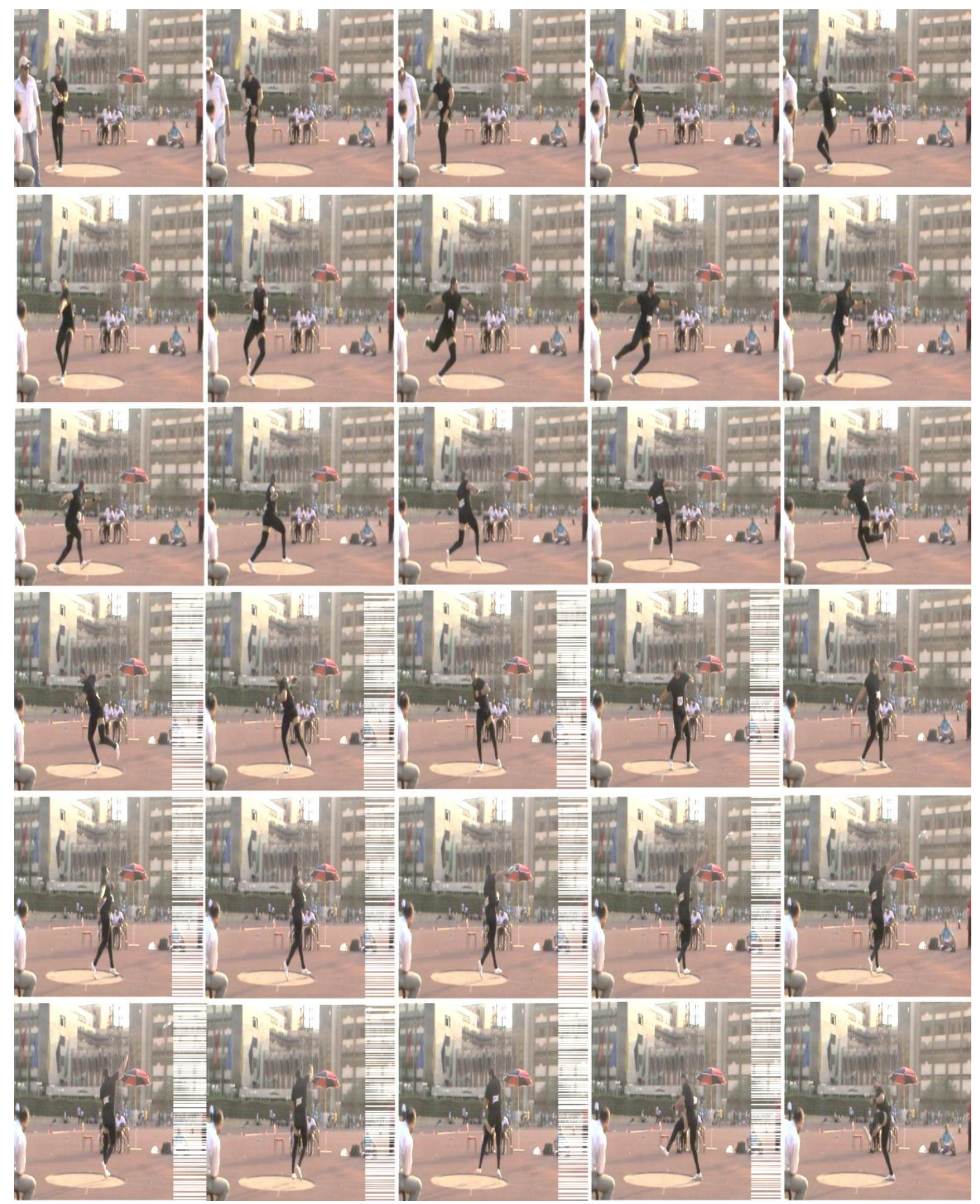


References:

1.Axel Knicker(1994). Kinematic analyses of the discus throwing competitions at the IAAF World Championships in Athletics, Stuttgart 1993,New Studies In Athletics, 9:3; 9-16..

2. Bartlett R.M. (1992). The biomechanics of the discus throw: A review. Journal of Sports Sciences, 10, 467-510.

3.Bing Yu, Jeffery Broker,Jay Silvester.(2002). A kinetic analysis of discus-throwing techniques, Sports Biomechanics. Volume 1, Issue 1, 2002, Pages 25 - 45

4. Ching-Hua Chiu (2008). Estimating the Optimal Release Conditions for World Record Holders in Discus, International Journal of Sport and Exercise Science, 1(1): 9-14.

5. Gideon Ariel, Alfred Finch, and Ann Penny(1997). BIOMECHANICAL ANALYSIS OF DISCUS THROWING AT THE 1996 ATLANTA OLYMPIC GAMES. 15 International Symposiums on

Biomechanics in Sports.

6. Helmar Hommel (2009).Biomechanical Analyses of Selected Events at the 12th IAAF World Championship in Athletics Berlin 15 23 August.
7. Hubbard, M., Cheng K.B. (2007). Optimal discus trajectories. Journal of Biomechanics, 40, 3650-3659.

8. MICHAEL YOUNG, Li Li (2005). Determination of Critical Parameters among elite female shot putters. Sports Biomech. 2005 Jul;4(2):131-48.

9. Steve Leigh,Hui Liu,Mont Hobbard,Bing Yu (2010). Individualized optimal release angles in discus throwing, Journal of Biomechanics, Volume 43, Issue 3 , Pages 540-545, 10 February 2010.

10. Steve Leigh,Hui Liu,Bing Yu,Mont Gross(2008). The relationship between discus throwing performance and combinations of selected technical parameters, Sports Biomech. 2008 May;7(2):173-93

11. Steve Leigh, Bing $Y u(2006)$. The influence of selected technical parameters on discus throwing performance, THE UNIVERSITY OF NORTH CAROLINA AT CHAPEL HILL, 99 pages; 1435045

12. Tidow, G. (1994). Model technique analysis sheets. Part IX: The discus throw. New Studies in Athletics, 9, 47-68

13. Vassilios Panoutsakopoulos, M.A. BIOMECHANICAL ANALYSIS OF THE MEN'S DISCUS THROW IN THE ATHENS 2006 I.A.A.F. WORLD CUP IN ATHLETICS 